\title{
Feasibility Study on Qualification of USP Dissolution Apparatus 1 and 2 Using the Enhanced Mechanical Calibration Procedure
}

\author{
Brian Yan*, Xujin Lu, and Ruben Lozano \\ Analytical \& Bioanalytical Development, Bristol-Myers Squibb Company \\ New Brunswick, NJ 08903
}

\begin{abstract}
A feasibility study was conducted in an analytical laboratory to evaluate implementation of the alternative procedure proposed by the FDA for enhanced mechanical calibration of USP dissolution Apparatus 1 and 2. The investigation started with a historical review of qualification data for more than 50 systems, generated through our current practice of combining USP mechanical calibration with the USP Performance Verification Test (PVT) using prednisone tablets. The data were compared with the more comprehensive FDA procedures and more stringent criteria for enhanced mechanical calibration. All the historical results met both USP and FDA criteria for shaft wobble, basket wobble, basket/paddle height check, and rotational speed and, in addition, passed the USP PVT. Shaft verticality was the mechanical parameter that infrequently did not meet the enhanced calibration criterion. Further investigations were conducted on a few representative dissolution systems to examine shaft verticality and determine what factors affect it. System levelness greatly affected whether shaft verticality met the tolerance. It is concluded from the results of the evaluation that it may be difficult for certain older units to consistently meet the criteria for shaft verticality. Therefore, our plan is to continue the current practice of a combination of USP mechanical calibration with PVT and to monitor shaft verticality data.
\end{abstract}

\section{INTRODUCTION}

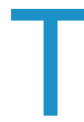

he types of dissolution apparatus used most often are USP Apparatus 1 (basket) and Apparatus 2 (paddle) (1). Current Good Manufacturing Practice (cGMP) regulations of the FDA mandate that laboratory instruments such as the dissolution apparatus must be calibrated at appropriate intervals following a program that has been established and written in a procedure (2). The traditional approach to dissolution apparatus calibration has been a combination of mechanical and chemical testing. The term "mechanical calibration" refers to the process of determining whether a test apparatus meets the dimensional and operational specifications of a regulatory compendium. "Chemical calibration" refers to the determination process using reference standard tablets. USP General Chapter $<711>$ describes mechanical calibration specifications and the Performance Verification Test (PVT) that uses prednisone reference tablets (3). For laboratories to maintain compliance with the USP standards, the combination of mechanical and chemical calibration has been the predominant procedure for dissolution apparatus qualification since 1978 (4).

Over the last several years, the Pharmaceutical Research and Manufacturers of America (PhRMA) and the FDA have been promoting the concept of "enhanced mechanical calibration." In January 2010 the FDA issued a Guidance for Industry, The Use of Mechanical Calibration of Dissolution

${ }^{*}$ Corresponding author.
Apparatus 1 and 2-Current Good Manufacturing Practice (cGMP) (5), in which they endorsed a set of mechanical calibration tests that are more comprehensive and more stringent than those described in the harmonized pharmacopeia including USP $<711>$. Details of the enhanced mechanical tests were published in an FDA Laboratory Operating Procedure (6) and in ASTM Method E2503-07 (7). Table 1 lists the mechanical calibration parameters along with their specifications from USP $<711>$ and the FDA-ASTM procedure. The enhanced FDA-ASTM calibration includes additional tests for shaft verticality (for both basket and paddle shafts in systems where they are different) and vessel verticality, and adds a quantitative specification for shaft wobble; these elements are not part of USP $<711>$. In addition, the FDA tolerances for shaft/vessel centering and rotational speed are tighter than those in the USP procedure. Carefully designed and stringent mechanical testing such as the FDA-ASTM procedure may be advantageous in guaranteeing adequate calibration by controlling mechanical variables within a tight range and thus minimizing sources of measurement variation. The FDA guidance states that the enhanced mechanical tests will satisfy cGMP requirements and can serve as a suitable alternative to the PVT. Employment of the enhanced procedure is therefore sometimes referred to as "mechanical only" calibration. Besides this recommendation from the FDA, which was based on earlier studies with PhRMA, other industry organizations such as Fédération Internationale 
Table 1. USP- and FDA-Recommended Specifications for Mechanical Calibration Parameters

\begin{tabular}{|c|c|c|}
\hline $\begin{array}{l}\text { Calibration } \\
\text { Parameter }\end{array}$ & $\begin{array}{c}\text { Specifications Based on } \\
\text { USP General Chapter } \\
<711>(3)\end{array}$ & $\begin{array}{l}\text { Specifications Based on } \\
\text { FDA Procedure (7) and } \\
\text { ASTM Standard (8) }\end{array}$ \\
\hline Shaft wobble & $\begin{array}{l}\text { Rotates smoothly without } \\
\text { significant wobble }\end{array}$ & $\leq 1.0 \mathrm{~mm}$ total runout \\
\hline \multirow[t]{2}{*}{ Shaft verticality } & $\mathrm{N} / \mathrm{A}$ (test is not specified) & $\begin{array}{l}\text { If a bubble level is used: } \\
\text { bubble must be within the } \\
\text { lines of the level. }\end{array}$ \\
\hline & & $\begin{array}{l}\text { If a digital device is used: } \\
\leq 0.5^{\circ} \text { from vertical }\end{array}$ \\
\hline Basket wobble & $\pm 1.0 \mathrm{~mm}$ runout & $\leq 1.0 \mathrm{~mm}$ total runout \\
\hline $\begin{array}{l}\text { Vessel/shaft } \\
\text { centering }\end{array}$ & $\leq 2 \mathrm{~mm}$ from centerline & $\leq 1.0 \mathrm{~mm}$ from centerline \\
\hline Vessel verticality & $\mathrm{N} / \mathrm{A}$ (test is not specified) & $\leq 1.0^{\circ}$ from vertical \\
\hline $\begin{array}{l}\text { Height check/ } \\
\text { paddle depth }\end{array}$ & $25 \pm 2 \mathrm{~mm}$ & $25 \pm 2 \mathrm{~mm}$ \\
\hline Rotational speed & $\pm 4 \%$ from target & \pm 2 rpm from target \\
\hline
\end{tabular}

Pharmaceutique (FIP) also support the replacement of chemical calibration with enhanced mechanical calibration (8). Under these circumstances, it is very important for pharmaceutical industry dissolution laboratories to examine their CGMP practices and establish strategies in response to the new calibration recommendations from regulatory agencies. Therefore, a study was performed in this laboratory to determine the feasibility of implementing the mechanical-only calibration process.

The current practice in this laboratory follows the USP approach of combining mechanical and chemical calibration (i.e., the PVT using prednisone tablets). This mechanical calibration procedure consists of a visual inspection of the system and its components along with testing for base plate levelness, shaft centering, paddle/basket depth, shaft verticality, spindle speed, shaft wobble, basket wobble, and vessel temperature. The specifications and tolerances applied to these tests are based on USP General Chapter $<711>$ Dissolution (3). The USP subsequently issued a Dissolution Toolkit (9) that describes best practices associated with the mechanical calibration testing, but this toolkit is not a compulsory standard for compliance. As a starting point for our feasibility study, we reviewed some of our most recent Performance Verification (PV) calibration records over a period of approximately one year (2009-2010) and compared them against the criteria of the FDA mechanical calibration procedure.

\section{EXPERIMENTAL}

\section{Dissolution Test Systems}

More than 50 dissolution systems in this laboratory were evaluated with a historical review of qualification data generated during 2009-2010. New experiments were conducted using the Distek Premiere 5100 (Systems 1 and 2), Agilent VK 7000 (Systems 3 and 5), and Agilent VK 7030 (System 4) dissolution test systems.

\section{USP Performance Verification Test}

USP prednisone tablets RS, Lot P0E203, was used for the calibration of all the dissolution systems in the lab from 2009 to 2010 for both setups of Apparatus 1 and Apparatus 2.

\section{Mechanical Calibration Tests}

USP mechanical calibration described in General Chapter $<711>$ was performed for all the dissolution systems in the lab from 2009 to 2010. A QA II Dissolution Systems Suitability Station, provided by Varian (currently Agilent), was used for the calibration in 2009 including the tests of base plate levelness, shaft centering, paddle/ basket depth, shaft verticality, spindle speed, shaft wobble, basket wobble, and vessel temperature. In 2010 a digital protractor (Model Pro 3600, Cat \# 31-040-9, Swiss Precision Instruments, Inc.) was used for the shaft verticality test, but the QA II Station was still used for the other tests.

\section{Shaft Verticality Test}

In addition to the paddle and basket shaft verticality data generated during the PV/calibration tests from 2009 to 2010, experiments were conducted on dissolution Systems 1,2 , and 3 to examine factors that might contribute to variability of the shaft verticality measurements. Further experiments were conducted on Systems 4 and 5 to investigate the correlation between bath levelness and shaft verticality. The digital protractor was used for all these experiments.

\section{RESULTS AND DISCUSSION}

Representative historical calibration results from three dissolution systems are shown for several mechanical parameters (Table 2). The USP and FDA criteria are listed in Table 1 . The vessel verticality test is an additional component of the FDA procedure, but it was not performed during our past calibrations because it is not a USP requirement. Wobble test results for basket and paddle shafts as well as for baskets met the FDA quantitative tolerance. The vessel centering results met the USP criterion, but numerical data were not recorded, only pass/ fail results. Therefore, evaluation of the historical data for vessel centering against the tighter FDA criterion could not be made. The results for height check/paddle depth met both the USP and FDA criteria, which are the same for this test. The results for rotational speed met both the USP criterion and the more stringent FDA criterion. However, for paddle and basket shaft verticality (Table 3 ), we found a few instances when some vessel positions did not meet the FDA criterion of $\leq 0.5^{\circ}$ from vertical, although they did meet our internal criterion of $\leq 1.5^{\circ}$. USP $<711>$ does not 
Table 2. Partial Mechanical Calibration Data

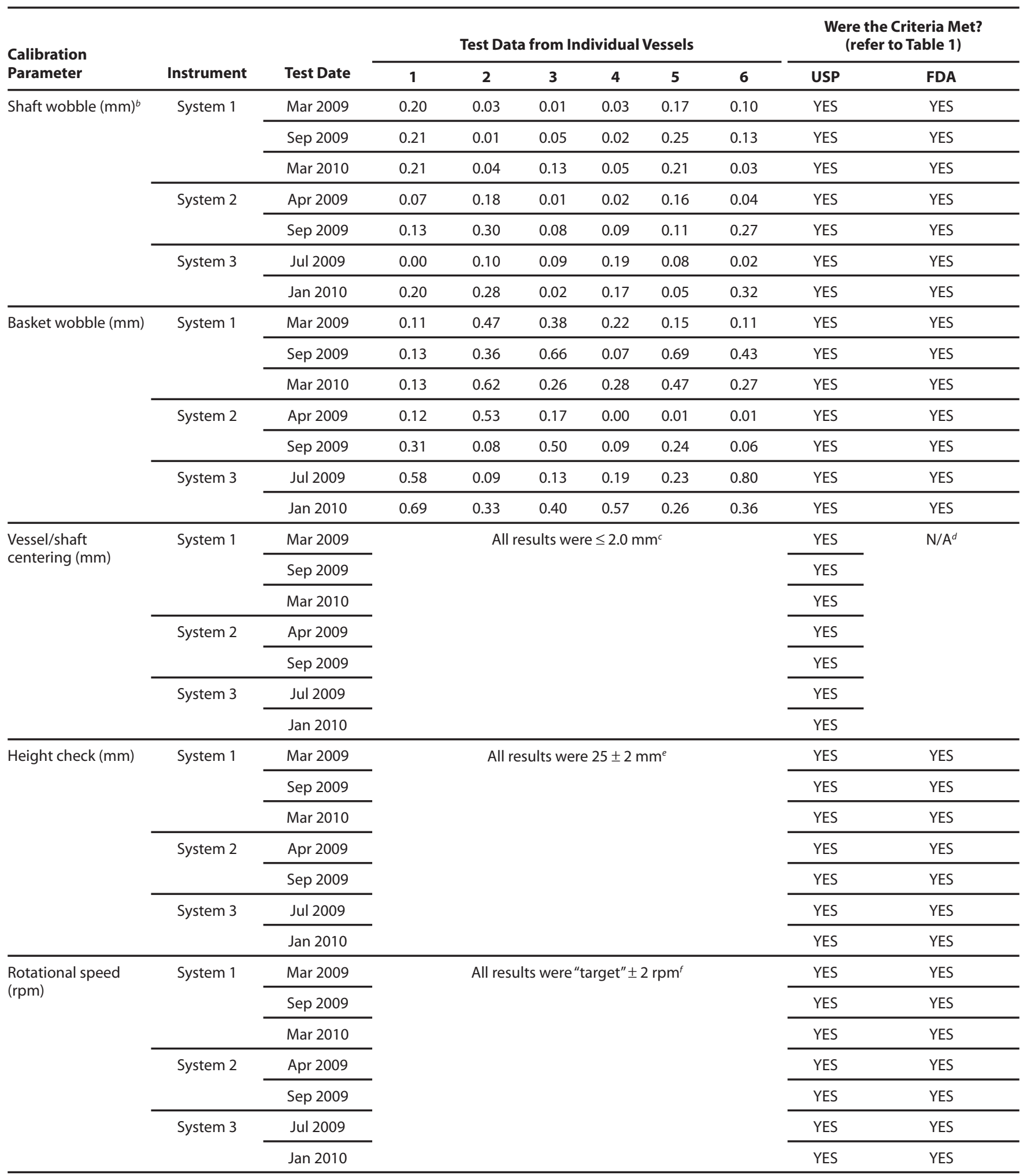

${ }^{a}$ Data for shaft verticality are summarized separately in Table 3. The vessel verticality test was not performed during the past calibrations because it is not required in USP.

${ }^{b}$ The wobble test was performed on both basket and paddle shafts. Both sets of data met the FDA criterion. Only the paddle shaft results are presented here.

'Data was recorded only as $\leq 2.0$, therefore exact results are not provided.

${ }^{d}$ FDA criterion cannot be evaluated because exact numerical results were not reported, only pass/fail results.

${ }^{e}$ Data was recorded only as $25 \pm 2$, therefore exact results are not provided.

'Data was recorded only as target \pm 2 , therefore exact results are not provided. 
Test data for individual vessels, measured along two directions ${ }^{a}$

$\left({ }^{\circ}\right.$ from vertical)

\begin{tabular}{|c|c|c|c|c|c|c|c|c|c|c|c|c|c|c|c|}
\hline \multirow{3}{*}{$\begin{array}{l}\text { Instrument } \\
\text { System } 1\end{array}$} & \multirow{4}{*}{$\begin{array}{c}\begin{array}{c}\text { Vendor and } \\
\text { Model }\end{array} \\
\text { Distek Premiere } \\
5100\end{array}$} & \multirow{4}{*}{$\begin{array}{c}\begin{array}{c}\text { Test } \\
\text { Date }\end{array} \\
\text { Mar } \\
2009\end{array}$} & \multirow{3}{*}{$\begin{array}{c}\begin{array}{c}\text { Shaft } \\
\text { Measured }\end{array} \\
\text { paddle }\end{array}$} & \multicolumn{12}{|c|}{ n vert } \\
\hline & & & & \multicolumn{2}{|c|}{1} & \multicolumn{2}{|c|}{2} & \multicolumn{2}{|c|}{3} & \multicolumn{2}{|c|}{4} & \multicolumn{2}{|c|}{5} & \multicolumn{2}{|c|}{6} \\
\hline & & & & 0.4 & 0.0 & 0.2 & 0.1 & 0.4 & 0.2 & 0.4 & 0.2 & 0.4 & 0.2 & 0.4 & 0.3 \\
\hline & & & basket & 0.4 & 0.2 & 0.2 & 0.2 & 0.4 & 0.2 & 0.3 & 0.2 & 0.3 & 0.1 & 0.4 & 0.2 \\
\hline & & \multirow{2}{*}{$\begin{array}{l}\text { Sep } \\
2009\end{array}$} & paddle & 0.3 & 0.2 & 0.3 & 0.2 & 0.5 & 0.1 & 0.4 & 0.2 & 0.5 & 0.1 & 0.5 & 0.3 \\
\hline & & & basket & 0.2 & 0.2 & 0.2 & 0.2 & 0.2 & 0.2 & ${\underline{0.7^{b}}}^{b}$ & 0.3 & 0.5 & 0.2 & 0.4 & 0.3 \\
\hline & & \multirow{2}{*}{$\begin{array}{l}\text { Mar } \\
2010\end{array}$} & paddle & 0.5 & 0.2 & 0.2 & 0.2 & 0.1 & 0.2 & 0.1 & 0.3 & 0.2 & 0.3 & 0.1 & 0.2 \\
\hline & & & basket & 0.4 & 0.2 & 0.1 & 0.3 & 0.4 & 0.4 & 0.3 & 0.2 & 0.3 & 0.3 & 0.3 & 0.3 \\
\hline \multirow[t]{4}{*}{ System 2} & \multirow{4}{*}{$\begin{array}{c}\text { Distek Premiere } \\
5100\end{array}$} & \multirow{2}{*}{$\begin{array}{l}\text { Apr } \\
2009\end{array}$} & paddle & 0.2 & 0.1 & 0.1 & 0.1 & 0.1 & 0.0 & 0.0 & 0.0 & 0.1 & 0.1 & 0.2 & 0.1 \\
\hline & & & basket & 0.2 & 0.1 & 0.0 & 0.0 & 0.1 & 0.1 & 0.0 & 0.1 & 0.0 & 0.1 & 0.1 & 0.0 \\
\hline & & \multirow{2}{*}{$\begin{array}{l}\text { Sep } \\
2009\end{array}$} & paddle & 0.2 & 0.0 & 0.0 & 0.3 & 0.1 & 0.1 & 0.1 & 0.1 & 0.1 & 0.3 & 0.1 & 0.2 \\
\hline & & & basket & 0.1 & 0.0 & 0.1 & 0.1 & 0.2 & 0.0 & 0.2 & 0.0 & 0.2 & 0.2 & 0.2 & 0.1 \\
\hline \multirow[t]{4}{*}{ System 3} & \multirow[t]{4}{*}{ Vankel VK 7000} & \multirow[t]{2}{*}{ Jul 2009} & paddle & 0.4 & 0.3 & 0.4 & 0.3 & 0.3 & 0.3 & 0.3 & 0.2 & 0.3 & $\underline{0.8}^{b}$ & 0.4 & $\underline{0.7}^{b}$ \\
\hline & & & basket & $\underline{\mathbf{0 . 7}}^{b}$ & $\underline{0.6}^{b}$ & 0.0 & 0.4 & 0.3 & $\underline{\mathbf{0 . 9}}^{b}$ & 0.5 & $\underline{\mathbf{0 . 6}}^{b}$ & 0.2 & 0.4 & 0.2 & 0.3 \\
\hline & & \multirow[t]{2}{*}{ Jan 2010} & paddle & 0.1 & 0.1 & 0.0 & 0.5 & 0.2 & 0.1 & 0.2 & 0.1 & 0.1 & 0.0 & 0.1 & 0.1 \\
\hline & & & basket & 0.2 & 0.2 & 0.4 & 0.0 & 0.1 & 0.1 & 0.0 & 0.2 & 0.2 & 0.4 & 0.2 & 0.2 \\
\hline
\end{tabular}

${ }^{a}$ The first value was measured with the protractor placed on the side edge of the shaft; the second value was measured with the protractor rotated $90^{\circ}$ to the front edge of the shaft. The FDA criterion is $\leq 0.5^{\circ}$ from vertical.

${ }^{b}$ Failed the FDA criterion of $\leq 0.5^{\circ}$.

stipulate tests for either shaft verticality or vessel verticality, but the USP has now included these tests in their Toolkit (9). Our observation about shaft verticality not consistently meeting the FDA criterion did not appear to be vendor-specific; we found some systems from both
Distek and Agilent (Varian) whose shaft verticality data did not always meet the FDA criterion. At the same time, however, these systems passed the USP PVT (Table 4).

We performed additional experiments on Systems 1,2 and 3 to examine factors that might contribute to variability

Table 4. USP PVT Data (Prednisone tablet testing ${ }^{a}$ )

\begin{tabular}{|c|c|c|c|c|c|c|c|c|}
\hline \multirow[b]{2}{*}{ Instrument } & \multirow[b]{2}{*}{ PV date } & \multirow[b]{2}{*}{ Apparatus } & \multicolumn{6}{|c|}{$\%$ Dissolved at $\mathbf{3 0} \mathrm{min}$} \\
\hline & & & Vessel 1 & Vessel 2 & Vessel 3 & Vessel 4 & Vessel 5 & Vessel 6 \\
\hline \multirow[t]{6}{*}{ System 1} & Mar 2009 & 1 & 66 & 68 & 61 & 69 & 58 & 57 \\
\hline & & 2 & 41 & 35 & 35 & 34 & 34 & 35 \\
\hline & Sep 2009 & 1 & 74 & 70 & 70 & 71 & 74 & 61 \\
\hline & & 2 & 40 & 39 & 35 & 37 & 34 & 36 \\
\hline & Mar 2010 & 1 & 64 & 72 & 66 & 65 & 60 & 63 \\
\hline & & 2 & 38 & 37 & 37 & 37 & 35 & 39 \\
\hline \multirow[t]{4}{*}{ System 2} & Apr 2009 & 1 & 64 & 65 & 63 & 61 & 73 & 59 \\
\hline & & 2 & 32 & 33 & 33 & 34 & 32 & 32 \\
\hline & Sep 2009 & 1 & 62 & 65 & 73 & 69 & 59 & 59 \\
\hline & & 2 & 34 & 34 & 34 & 36 & 38 & 34 \\
\hline \multirow[t]{4}{*}{ System 3} & Jul 2009 & 1 & 70 & 69 & 69 & 68 & 69 & 64 \\
\hline & & 2 & 34 & 33 & 37 & 35 & 40 & 37 \\
\hline & Jan 2010 & 1 & 72 & 70 & 73 & 73 & 67 & 69 \\
\hline & & 2 & 44 & 41 & 42 & 42 & 41 & 39 \\
\hline
\end{tabular}

${ }^{a}$ USP prednisone tablets RS, Lot P0E203, was used. For this lot, the criteria are 47-82\% dissolved for Apparatus 1, and 30-57\% dissolved for Apparatus 2. 


\begin{tabular}{|c|c|c|c|c|c|c|}
\hline \multirow[b]{2}{*}{ Instrument } & \multicolumn{3}{|c|}{ Measurements in 1st Direction } & \multicolumn{3}{|c|}{ Measurements in 2nd Direction } \\
\hline & $\begin{array}{l}\text { System levelness along } \\
\text { x-axis ( }{ }^{\circ} \text { from horizontal) }\end{array}$ & Vessel & $\begin{array}{l}\text { Shaft verticality along the } \\
\text { side edge of shaft } \\
\text { ( }{ }^{\circ} \text { from vertical) }\end{array}$ & $\begin{array}{l}\text { System levelness along } \\
\text { y-axis ( }{ }^{\circ} \text { from horizontal) }\end{array}$ & Vessel & $\begin{array}{l}\text { Shaft verticality along the } \\
\text { front edge of shaft } \\
\text { ( }{ }^{\circ} \text { from vertical) }\end{array}$ \\
\hline \multirow[t]{6}{*}{ System 1} & 0.02 & 1 & 0.05 & 0.05 & 1 & 0.35 \\
\hline & & 2 & 0.02 & & 2 & 0.26 \\
\hline & & 3 & 0.18 & & 3 & 0.31 \\
\hline & & 4 & 0.05 & & 4 & 0.29 \\
\hline & & 5 & 0.00 & & 5 & 0.23 \\
\hline & & 6 & 0.14 & & 6 & 0.15 \\
\hline \multirow[t]{6}{*}{ System 2} & 0.06 & 1 & 0.14 & 0.03 & 1 & 0.15 \\
\hline & & 2 & 0.16 & & 2 & 0.06 \\
\hline & & 3 & 0.42 & & 3 & 0.07 \\
\hline & & 4 & 0.35 & & 4 & 0.11 \\
\hline & & 5 & 0.30 & & 5 & 0.04 \\
\hline & & 6 & 0.10 & & 6 & 0.10 \\
\hline \multirow[t]{6}{*}{ System 3} & 0.33 & 1 & $\underline{\mathbf{0 . 7 4}}^{a}$ & 0.05 & 1 & 0.04 \\
\hline & & 2 & $\underline{0.74}^{a}$ & & 2 & 0.04 \\
\hline & & 3 & $\underline{0.81}^{a}$ & & 3 & 0.02 \\
\hline & & 4 & $\underline{\mathbf{0 . 8 7}}^{a}$ & & 4 & 0.07 \\
\hline & & 5 & ${\underline{0.93^{a}}}^{a}$ & & 5 & 0.05 \\
\hline & & 6 & $\underline{0.93}^{a}$ & & 6 & 0.05 \\
\hline
\end{tabular}

${ }^{a}$ Failed the FDA criterion of $\leq 0.5^{\circ}$.

of the shaft verticality measurements. We focused on two particular elements and their affect on shaft verticality: (1) the levelness of the system base plate and (2) the location of the reference point for zeroing the device if a digital device is used to measure verticality. Table 5 shows data for paddle-shaft verticality and system levelness for Systems 1, 2, and 3 that were measured using a digital protractor. Measurements were made in two orthogonal directions by placing the protractor along the shaft vertical axis, first along the side edge of the shaft, then rotating the protractor $90^{\circ}$ to the front edge of the shaft, essentially as described in the FDA (6) and ASTM (7) procedures. To establish a zero reference point for both verticality and system levelness measurements, the protractor was zeroed using the bench surface where the system was located. For Systems 1 and 2, the shaft verticality in both orthogonal directions was within the $0.5^{\circ}$ limit specified by the FDA procedure. However, for System 3, shaft verticality exceeded the limit in the first direction but was still well within the limit in the second direction. It was suspected that the base plate of System 3 was not level along the $x$-axis (refer to orientation in Figure 1), which would cause nonverticality along the side edge of the shaft. This hypothesis was corroborated by the levelness data for System 3 (Table 5). This shows a much higher slope along the $x$-axis of the base plate, which corresponds to the direction in which the shaft failed the verticality tolerance (i.e., along its side edge). The base plate was much more level in the opposite $y$-axis, which would affect verticality of the shaft along its front edge, where the verticality criterion was met. The base plates of Systems 1 and 2, which passed the criteria for shaft verticality, were level in both directions.

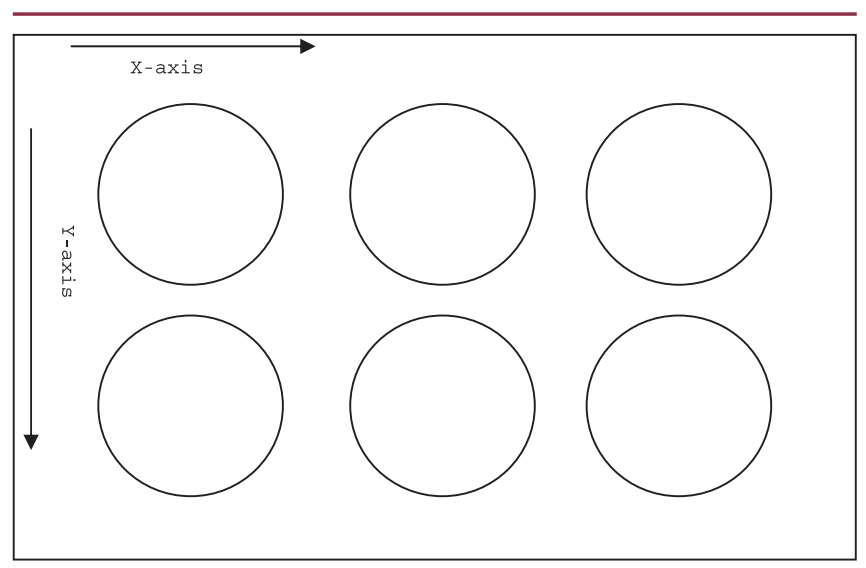

Figure 1. Top view of bath base plate. 
Table 6. Shaft Verticality Data Before and After Adjustment of System Levelness ${ }^{a}$

\begin{tabular}{lcccc}
\hline & \multicolumn{4}{c}{ Shaft Verticality $\left({ }^{\circ}\right.$ from vertical) } \\
\cline { 2 - 5 } & \multicolumn{2}{c}{ Along 1st Direction } & \multicolumn{2}{c}{ Along 2nd Direction } \\
\cline { 2 - 5 } Vessel & $\begin{array}{c}\text { Before } \\
\text { Levelness } \\
\text { Adjustment }\end{array}$ & $\begin{array}{c}\text { After Levelness } \\
\text { Adjustment }\end{array}$ & $\begin{array}{c}\text { Before } \\
\text { Levelness } \\
\text { Adjustment }\end{array}$ & $\begin{array}{c}\text { After Levelness } \\
\text { Adjustment }\end{array}$ \\
\hline 1 & 0.17 & 0.22 & 0.44 & 0.18 \\
\hline 2 & 0.29 & 0.14 & 0.48 & 0.18 \\
\hline 3 & 0.15 & 0.15 & $\mathbf{0 . 5 7 ^ { b }}$ & 0.29 \\
\hline 4 & 0.09 & 0.10 & 0.47 & 0.23 \\
\hline 5 & 0.08 & 0.13 & 0.49 & 0.23 \\
\hline 6 & 0.12 & 0.05 & 0.38 & 0.13 \\
\hline
\end{tabular}

aA VK 7030 unit was used, designated as "System 4."

${ }^{b}$ Failed the FDA criterion of $\leq 0.5^{\circ}$.

We then examined how shaft verticality would be affected when the levelness of the system base plate was adjusted. We could not perform this experiment on System 3 because that model (an older VK 7000) lacks the feature of levelness adjustments; therefore, we used System 4 (VK 7030 model), which does have this feature. Data are shown in Table 6. For this particular system, shaft verticality measurements along the first direction were high relative to those along the second direction. An examination of the bubble level on this system showed that the bubble was off-center. The legs of the system were adjusted until the bubble was centered. A second set of shaft verticality measurements was then taken. The values obtained after leveling the base plate were much lower, and all of them were well within the $0.5^{\circ}$ limit.

To further investigate the correlation between bath levelness and shaft verticality, more measurements were performed on System 5, which is part of a Multidose automated dissolution testing station, since our laboratories possess quite a few of these systems. Data collection was conducted twice. In the first set of measurements, the protractor was zeroed on the bench surface where the dissolution system was located. In the second set, the protractor was zeroed on the top of the platform where the top of the shafts are housed, thereby eliminating the influence of bath levelness on shaft verticality. The data are summarized in Table 7. The second set of results, where the influence of bath levelness was removed, shows much lower deviation from verticality than the first data set but does not indicate the true verticality of the shafts. This finding corroborates the observation from the previous experiments that system levelness plays a critical role in determining shaft verticality. The apparent improvement in verticality observed when using the instrument platform rather than the bench demonstrates the importance of
Table 7. Shaft Verticality Data Using Bench Surface vs. System Platform as Zero Reference Point for the Digital Protractor ${ }^{a}$

\begin{tabular}{lcccc}
\hline & \multicolumn{4}{c}{ Shaft Verticality ( ${ }^{\circ}$ from vertical) } \\
\cline { 2 - 5 } Vessel & $\begin{array}{c}\text { Along 1st Direction } \\
\text { Reference }\end{array}$ & $\begin{array}{c}\text { Platform as } \\
\text { Reference }\end{array}$ & $\begin{array}{c}\text { Alonch 2nd Direction } \\
\text { Reference }\end{array}$ & $\begin{array}{c}\text { Platform as } \\
\text { Reference }\end{array}$ \\
\hline 1 & $\underline{\mathbf{0 . 7 3}}^{b}$ & 0.48 & 0.39 & 0.07 \\
\hline 2 & $\underline{\mathbf{0 . 6 2}}^{b}$ & 0.46 & 0.33 & 0.14 \\
\hline 3 & $\underline{\mathbf{0 . 7 2}}^{b}$ & 0.38 & 0.29 & 0.14 \\
\hline 4 & $\underline{\mathbf{0 . 5 9}}^{b}$ & 0.45 & 0.26 & 0.08 \\
\hline 5 & $\underline{\mathbf{0 . 6 7}}^{b}$ & 0.43 & 0.23 & 0.15 \\
\hline 6 & 0.47 & 0.44 & 0.26 & 0.13 \\
\hline
\end{tabular}

${ }^{a}$ A VK 7000 unit was used, designated as "System 5."

${ }^{b}$ Failed the FDA criterion of $\leq 0.5^{\circ}$.

choosing the correct point of reference when using a digital device to measure shaft verticality. It must be a level surface such as a bench and not a point somewhere on the apparatus such as the base plate. Better consistency of testing with digital measuring devices can be ensured by having the calibration protocols designate a reference point location.

Several older VK 7000 systems that lack the feature of self-adjusting system levelness are still used in our laboratories. For one of these units, the base plate had a relatively high degree of inclination from levelness (although it was still within USP tolerance, and there is no impact to the GMP samples tested on this system). For this system, a relationship between the high base plate inclination and greater deviation of shaft verticality was demonstrated such that the stringent FDA verticality tolerance was not met. However, the tolerance cannot be corrected on the VK 7000 units because their levelness cannot be adjusted easily. Therefore, switching now to the new mechanical-only calibration procedure carries a risk. These older systems may not pass qualifications based on the enhanced testing when they would otherwise meet the standards of USP mechanical calibration combined with PVT, which serves as the holistic test to ensure system qualification. Therefore, it was decided to continue our current calibration procedure (mechanical and PVT) versus USP $<711>$ criteria. We will monitor results against the enhanced mechanical calibration criteria, with particular emphasis on shaft verticality, and gradually convert to the mechanical-only testing procedure when all of the old VK 7000 systems are retired from our fleet.

\section{CONCLUSIONS}

Historical calibration data from many representative dissolution systems in our analytical laboratories were reviewed. Evaluations were performed on how these 
systems, which met the USP criteria for mechanical calibration combined with PVT, would fare if the more stringent criteria of enhanced mechanical calibration were applied against the data. All the results met both USP and FDA criteria for shaft wobble, basket wobble, height check, and rotational speed, and passed the USP PVT. Shaft verticality was the mechanical parameter that infrequently did not meet the enhanced calibration criterion. System levelness can critically affect shaft verticality and is likely to be the primary cause of verticality readings falling outside the tolerance. When measuring shaft verticality with a digital device, it is imperative to zero the device on an appropriate level surface as a reference point. Because it may be difficult for certain older units to consistently meet the enhanced criteria of mechanical-only calibration, this laboratory will continue the current practice of combining USP mechanical calibration with the USP PVT.

\section{ACKNOWLEDGMENTS}

The authors thank Mr. Michael Bereski and Baseline Service, Inc., for their collaboration and support during the investigation.

\section{REFERENCES}

1. Shah, V.P.; Konecny, J. J.; Everett, R. L.; McCullough, B.; Noorziradeh, A. C.; Skelly, J. P. In Vitro Dissolution Profile of Water Insoluble Drug Dosage Forms in the Presence of Surfactants. Pharm. Res. 1989, 6 (7), 612-618.

2. Current Good Manufacturing Practice for Finished Pharmaceuticals. Code of Federal Regulations, Part 211, Title 21, Section 211.160(b)(4), 2002.
3. <711> Dissolution. In United States Pharmacopeia and National Formulary USP 33-NF 28, The United States Pharmacopeial Convention, Inc.: Rockville, MD, 2010.

4. Foster, T.; Brown, W. USP Dissolution Calibrators: Reexamination and Appraisal.Dissolution Technol. 2005, $12(1), 6-8$.

5. The Use of Mechanical Calibration of Dissolution Apparatus 1 and 2-Current Good Manufacturing Practice (CGMP); Guidance for Industry; U.S.

Department of Health and Human Services, Food and Drug Administration, Center for Drug Evaluation and Research (CDER), U.S. Government Printing Office: Washington, DC, January, 2010.

6. Mechanical Qualification of Dissolution Apparatus 1 and 2; DPA-LOP.002; U.S. Department of Health and Human Services, Food and Drug Administration, Division of Pharmaceutical Analysis, U.S. Government Printing Office: Washington, DC, 2006.

7. Standard Practice for Qualification of Basket and Paddle Dissolution Apparatus; ASTM Standard E2503-07; ASTM International: West Conshohocken, PA, 2007.

8. Brown, C.; Buhse, L.; Friedel, H.-D.; Keitel, S.; Kraemer, J.; Morris, J. M.; Stickelmeyer, M.; Yomota, C.; Shah, V. P. FIP Position Paper on Qualification of Paddle and Basket Dissolution Apparatus. AAPS PharmSciTech 2009, 10 (3), 924-927.

9. Dissolution Toolkit Procedures for Mechanical Calibration and Performance Verification Test Apparatus 1 and Apparatus 2; Version 2.0; The United States Pharmacopeial Convention, Inc.: Rockville, MD, 2010. 


\title{
Corrigendum to "Feasibility Study on Qualification of USP Dissolution Apparatus 1 and 2 Using the Enhanced Mechanical Calibration Procedure"
}

\author{
Brian Yan, Xujin Lu, and Ruben Lozano \\ Analytical \& Bioanalytical Development, Bristol-Myers Squibb Company, \\ New Brunswick, NJ 08903-0191
}

Dissolution Technologies 2011, 18 (2), 17-23.

W ith regard to our article,"Feasibility Study on Qualification of USP Dissolution Apparatus 1 and 2 Using the Enhanced Mechanical Calibration Procedure," which appeared in Dissolution Technologies, Vol. 18, Issue 2, pp 17-23 (May 2011), the authors wish to issue a correction concerning statements that we attributed to the VK7000 dissolution test system. We inaccurately stated in several instances that this model "lacks the feature of levelness adjustment," when in fact, it does possess that feature, thus allowing the unit levelness to be adjusted properly, if necessary. We apologize to Agilent for the oversight. It was unintended for our paper to focus on a comparison of systems or to point out deficiencies. Rather, the main objective was to demonstrate the relationship between system levelness and shaft verticality and its potential impact on meeting the mechanical calibration criteria.

Also, regarding use of the digital device to measure system levelness and shaft verticality, the authors wish to clarify that the bench surface was confirmed to be level relative to the earth (i.e., the lab floor), thereby justifying use of the bench surface as the zero reference point for the digital device. To ensure that digitally recorded measurements of system levelness and shaft verticality are accurate, it is important not to assume automatically that the lab bench is vertical relative to earth level (true zero). 